\title{
Effect of Manual Ivy Removal on Seedling Recruitment in Forest Park, Portland, OR
}

\author{
Katelin D. Stanley \& Dr. David W. Taylor \\ Department of Biology, University of Portland, Oregon \\ Student:kstanley@bio.fsu.edu,Mentor:taylorda@up.edu
}

\begin{abstract}
English and Irish ivy (Hedera helix and H. hibernica) are invasive lianas which have become especially intrusive in the Pacific Northwest, as evidenced by their invasion of many areas in Forest Park, Portland, OR. The most common strategy for ivy control is currently manual removal, though the potential consequences of this method have not been well studied. The purpose of this study was to evaluate the effectiveness of manual ivy removal with respect to its influence on native plant diversity, abundance, species richness, and evenness by comparing these parameters in $1-\mathrm{m}^{2}$ plots manually cleared of ivy to paired control plots. Prior to plot establishment, evidence of deer herbivory of ivy was observed at this site. Four weeks after manual removal, treated plots were less diverse and hosted a lower abundance of native plants than control plots. Ten weeks after ivy removal, treated and control plots were equally diverse, and treated plots showed greater abundance of plant cover than controls. This trend persisted at twenty-six weeks after treatment. Treated and control plots were not significantly different in species richness or evenness at any time. These results suggest that manual ivy removal temporarily disturbs native plant life, but the negative effects are overcome as quickly as ten weeks after treatment, at which time native plants are more successful. Manual removal as a method to control ivy in this region appears effective within one growing season
\end{abstract}

\section{KEYWORDS}

English Ivy, Irish Ivy, Invasive Species, Pacific Northwest, Forest Park, Hedera helix, Hedera hibernica

\section{INTRODUCTION}

English ivy (Hedera helix) and Irish ivy (Hedera hibernica), henceforth collectively denoted "ivy," are perennial lianas native to Europe which have escaped cultivation and become invasive in North America, especially the Pacific Northwest (PNW). ${ }^{1}$ Washington and Oregon have listed ivy as a noxious weed, and Oregon has even placed it under quarantine. ${ }^{2}$ Though ivy can reproduce sexually, in which its seeds are dispersed by birds, the success of ivy as an invasive species is more commonly attributed to its vegetative reproduction. ${ }^{3}$ Ivy demonstrates rapid vegetative growth and has been reported to ascend trees at a rate of up to $10 \mathrm{~m}$ per year using adventitious roots, resulting in both dominance of the understory and influence on forest canopies. ${ }^{4,5}$ Likely due to its evergreen nature and tolerance of heavy canopy cover, direct sunlight, and a wide range of soil pHs, ivy outcompetes native plant communities in forested areas. ${ }^{6,7}$ Ivy has been known to further disrupt forests by reducing root and leaf development of trees, ${ }^{8,9,10}$ predisposing host trees to weather-related damage, ${ }^{11}$ and preventing understory regeneration and growth by formation of near monotypic ivy mats. ${ }^{10,12}$ Ivy dominance has been correlated with alterations in soil nutrient contents, ${ }^{13}$ and these changes may have lasting impacts on native plant and animal communities. Furthermore, loss of native species diversity and abundance has the potential to reduce the functioning of the ecosystem. ${ }^{14}$

The PNW is a unique and sensitive region home to several endemic species such as the bigleaf maple, vine maple, and inside-out flower. The former two species may suffer from ivy's climbing ability, and each may experience displacement and increased competition from ivy groundcover. The hilly, suburban regions of Portland, Oregon are overrun by ivy in many places, and ivy has encroached on the city's largest urban forest reserve, Forest Park, where it forms dense mats and 
climbs native trees in disturbed areas. Because ivy invasion poses a direct threat to this region already experiencing anthropogenic habitat loss, an examination of ivy control methods is necessary to determine whether management efforts are being productively applied in this area.

Several studies examining possible solutions to the problem of invasive ivy have been conducted in recent years, with several methods of removal showing limited success. Control of ivy using herbicides has not proven effective due to the plant's thick cuticle ${ }^{15}$ though some exceptions have been indicated. ${ }^{16,17}$ Repeated burning and goat browsing have shown success in reducing ivy cover, but the efficacy of these methods is diminished by their significant time and resource requirements. ${ }^{10,18}$ To date, the favored ivy control strategy is manual removal - pulling the vines from the ground and vertical surfaces. ${ }^{19,20,21}$

While manual removal avoids many disadvantages of herbicidal and other treatments, this method, too, may have significant negative effects due to its disturbance of the soil and neighboring plant life. ${ }^{19}$ These effects have been considered minor relative to the consequences of ivy invasion, but few studies have investigated this assumption. The purpose of this study is to evaluate the effectiveness of manual ivy removal in terms of its impact on native plant diversity, abundance, species richness, and evenness. Because removing ivy has the potential to increase light and nutrient availability for native plants, it is hypothesized that greater native plant diversity and abundance will be observed in plots cleared of ivy over control plots.

\section{MATERIALS AND METHODS}

Ten pairs of 1-m ${ }^{2}$ ivy-covered (99-100\% cover) plots were marked with wooden stakes in northeast Forest Park (45.5924 N, -122.785 W). This location was chosen for its dense understory ivy growth, relatively low degree of slope, and ease of access, with plots sheltered from view yet still within 20 meters of a well-maintained trail. For each pair of plots, one was randomly designated as the treated plot and the other the control. Habitat characteristics such as nearby nursery logs or trees, overhanging branches, presence of surrounding plant species, and unique soil conditions were noted. Percent cover of all plant species was recorded using a 1- $\mathrm{m}^{2}$ PVC quadrat divided into $10 \times 10-\mathrm{cm}$ squares, and a photograph was taken for both control and treated plots upon establishment. Due to their morphological and niche similarities, the two species of ivy, if they were both present, were not differentiated. Plots were established over the course of approximately three weeks in February 2014.

All treated plots were manually cleared of ivy by hand-pulling and use of clippers on February 15th. As woody lateral stems often formed extensive under- and above-ground lattices, the entire underlying ivy network in each plot was removed. Care was taken not to tread in either plot during the removal process. Some native individuals remained after ivy removal, but most were unavoidably uprooted during the process. This effect did not appear dramatic, as the pre-treated average native plant cover for all plots excluding moss was only 10.4. Example photographs for control and treated plots before and after ivy removal are shown in Figure 1.
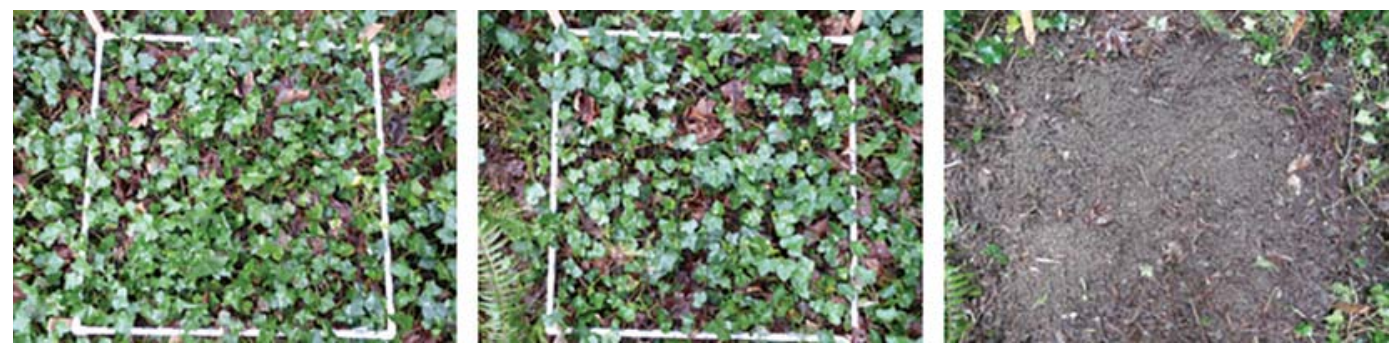

Figure 1. Example control plot (left) and treated plot photographs before (center) and after (right) manual ivy removal. Typical soil disturbance and incidental removal of detritus sustained during the clearing process is represented in the in the cleared treated plot (right). 
Sites were surveyed for vegetation three times after ivy removal: after four weeks (late Marchearly April), after ten weeks (early May), and after twenty-six weeks (mid-September). For each survey, the same quadrat used for plot establishment was placed with the corners at each stake. Percent cover of all plant species in the quadrat was recorded as the number of squares from which the species was observed to be growing. Any ivy root matter which had been overlooked during clearing (an average of 3.1 percent cover per plot) and new ivy growth were included in this survey. Due to the dense ivy mat and, in some plots, extensive growth of Hydrophyllum tenuipes (Pacific waterleaf), and manual manipulation of vegetation was necessary to ensure accurate records of plant presence. Control and treated plots were photographed after each survey. Plants were identified with help from a field guide ${ }^{22}$ and confirmed via taxonomic literature. ${ }^{23}$

Shannon-Weaver diversity indices were calculated based on percent cover values for each treated and control plot. Abundance of native plants was determined using the sum of percent cover values for all plant species in treated and control plots. Species richness and species evenness of all plots were also calculated. Percent cover of ivy was excluded from all calculations. Each variable was tested for significance using two-tailed t-tests. Euclidean distances were used to compare the statistical similarities of plot pairs after each survey; high values indicated high dissimilarity and low values indicated greater similarity between treated and control plots.

\section{RESULTS}

Regrowth of ivy into treated plots

By ten weeks after ivy removal, all but one treated plot contained at least one percent cover of ivy. Twenty-six weeks after treatment, ivy was observed in all treated plots, achieving an average of 12 percent cover.

\section{Native Plant Growth and Emergent Species}

Representative photographs of a treated plot at each of the survey dates are shown in Figure 2. In March/April, four weeks after ivy removal, seedlings were emerging in both control and treated plots, with a total of 13 species observed. After ten weeks, in May, native plant growth was abundant and six additional species were identified. In September, which was after a rather warm and dry summer, little plant growth was observed, though two additional species were identified. All 21 identifiable plant species that emerged during the survey period, with the exception of ivy, were Pacific Northwest natives. Though they could not be identified due to their minimal growth, several other morphologically distinct seedlings were included in analysis as unknowns. 

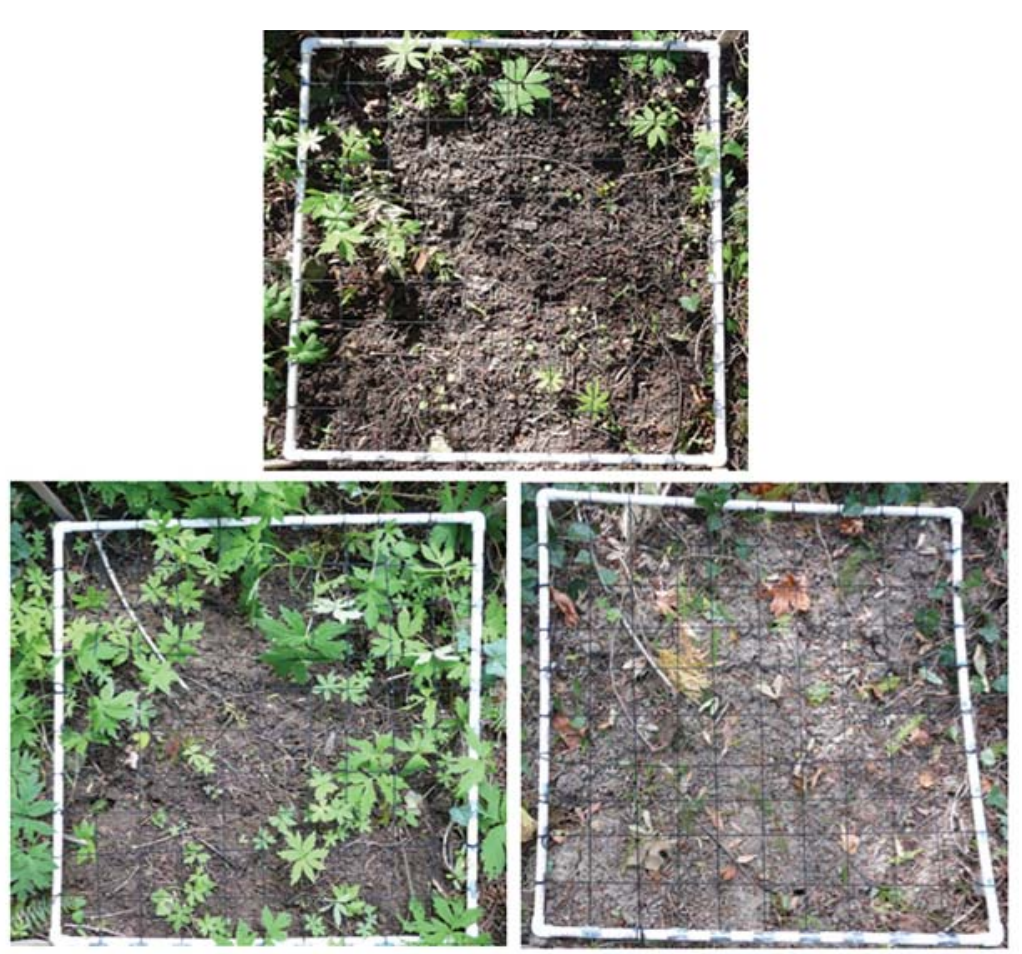

Figure 2. Example treated plot photographs after four weeks (top), after ten weeks (bottom left), and after twenty-six weeks (bottom right). This plot is representative of the average amount of growth observed in treated plots, though some plots showed much less cover and others showed much more. Individuals only observed as pairs of cotyledons, which proved difficult to identify, can be seen in each plot (see discussion). 


\begin{tabular}{|c|c|}
\hline Scientific Name & Common Name \\
\hline Acer circinatum & Vine maple \\
\hline Acer macrophyllum & Bigleaf maple \\
\hline Corylus spp.* & Hazelnut \\
\hline Hedera spp. & English or Irish ivy \\
\hline Hydrophyllum tenuipes & Pacific waterleaf \\
\hline Berberis nervosa & Dull Oregon grape \\
\hline Maianthemum racemosum ${ }^{*}$ & False Solomon's seal \\
\hline Oemleria cerasiformis & Indian plum \\
\hline Osmorhiza spp. & Sweet cicely \\
\hline Polypodium glycyrrhiza & Licorice fern \\
\hline Prosartes smithii & Hooker's fairy bells \\
\hline Rubus parviflorus & Thimbleberry \\
\hline Rubus spectabilis & Salmonberry \\
\hline Rubus ursinus & Trailing blackberry \\
\hline Smilacina racemosa & False Solomon's seal \\
\hline Trillium ovatum & Pacific trillium \\
\hline Unknown & Moss (unidentified) \\
\hline Unknown & Other bryophyte (unidentified; possible liverwort) \\
\hline Unknown, possibly Athyrium filix-femina & Fern (unidentified; possibly Common lady fern) \\
\hline Vancouveria hexandra & White inside-out flower \\
\hline Viola glabella & Stream violet \\
\hline
\end{tabular}

Table 1. List of identified species found in treated and control plots. Species in bold indicate those which were observed in early May, but not during late March/early April. An asterisk $\left({ }^{*}\right)$ denotes species observed only in September.

Effect of ivy removal on native plant diversity, abundance, species richness, and evenness

Four weeks after ivy removal, treated plots were less diverse (mean \pm SEM for Shannon $=1.15$ \pm 0.08 ) and less covered by native species (mean \pm SEM for total native cover $127 \pm 17$ ) than the control plots (Shannon $=1.35 \pm 0.06$, total native cover $159 \pm 15$ ) (Figure 3). Species richness and evenness were comparable between treated and control plots (mean \pm SEM for treated plots $=5.7 \pm$ 0.6 , control plots $=6.5 \pm 0.8$ ), and this trend persisted through subsequent surveys. Ten weeks after ivy removal, treated plots were as diverse (mean \pm SEM for Shannon $=1.08 \pm 0.08)$ as control plots (mean \pm SEM $=1.03 \pm 0.08$ ) and covered by a higher abundance of native species (mean \pm SEM for total native cover of treated plots $=137 \pm 9$ and for control plots $119 \pm 13$ ). This trend lasted until the 26th week after ivy removal (Figure 3, Table 2). 


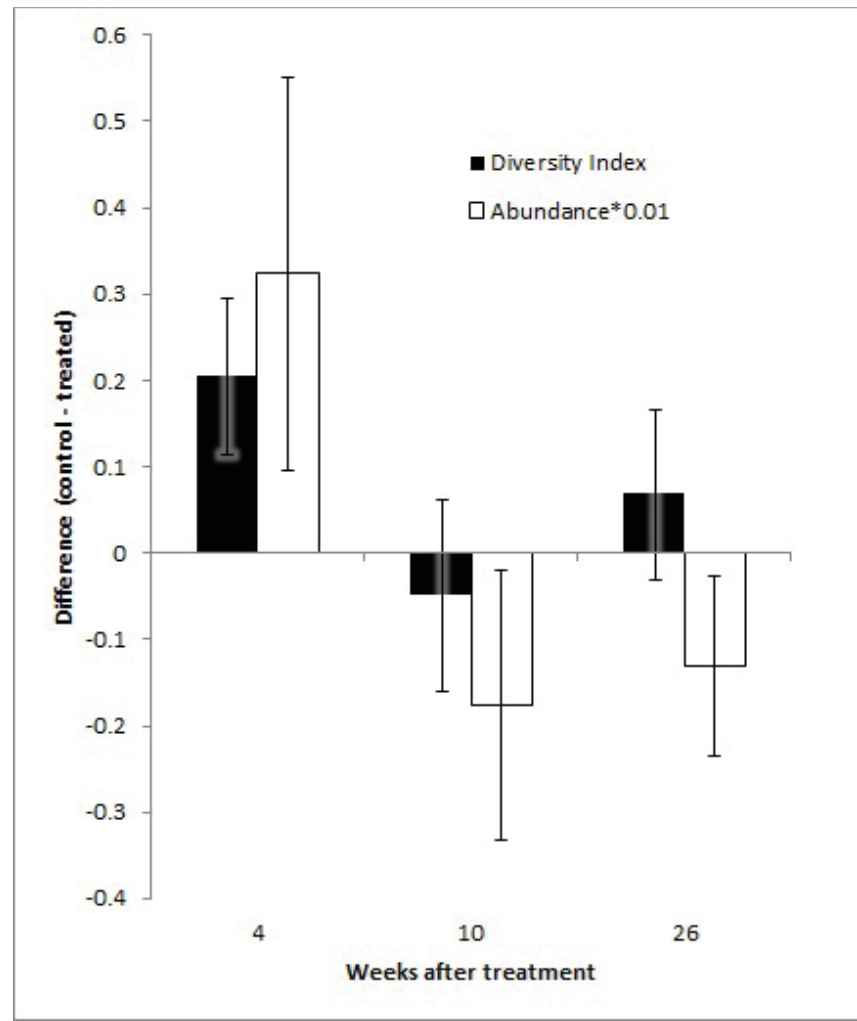

Figure 3. Average difference (control - treated plot) in Shannon diversity index and abundance (x0.01). Error bars show standard errors of the difference between two means.

\begin{tabular}{|c|c|c|c|c|c|c|c|c|c|c|c|c|}
\hline \multirow{2}{*}{$\begin{array}{c}\text { Time after } \\
\text { removal }\end{array}$} & \multicolumn{3}{|c|}{$\begin{array}{l}\text { Shannon-Weaver } \\
\text { Diversity Index }\end{array}$} & \multicolumn{3}{|c|}{ Abundance } & \multicolumn{3}{|c|}{ Species Richness } & \multicolumn{3}{|c|}{ Evenness } \\
\hline & Treated & Control & $p$ & Treated & Control & $p$ & Treated & Control & $p$ & Treated & Control & $p$ \\
\hline $\begin{array}{l}\text { Four } \\
\text { weeks }\end{array}$ & $\begin{array}{l}1.15 \pm \\
0.08\end{array}$ & $\begin{array}{c}1.35 \pm \\
0.06\end{array}$ & 0.0143 & $\begin{array}{c}127 \pm \\
17\end{array}$ & $\begin{array}{c}159 \pm \\
15\end{array}$ & 0.0258 & $\begin{array}{c}5.7 \pm \\
0.6\end{array}$ & $\begin{array}{c}6.5 \pm \\
0.8\end{array}$ & 0.415 & $\begin{array}{c}0.69 \pm \\
0.03\end{array}$ & $\begin{array}{c}0.77 \pm \\
0.04\end{array}$ & 0.144 \\
\hline $\begin{array}{c}\text { Ten } \\
\text { weeks }\end{array}$ & $\begin{array}{c}1.08 \pm \\
0.08\end{array}$ & $\begin{array}{c}1.03 \pm \\
0.08\end{array}$ & 0.568 & $\begin{array}{c}137 \pm \\
9\end{array}$ & $\begin{array}{c}119 \pm \\
13\end{array}$ & 0.0422 & $\begin{array}{c}7.0 \pm \\
0.8\end{array}$ & $\begin{array}{c}6.2 \pm \\
0.8\end{array}$ & 0.477 & $\begin{array}{c}0.57 \pm \\
0.02\end{array}$ & $\begin{array}{c}0.60 \pm \\
0.03\end{array}$ & 0.447 \\
\hline $\begin{array}{c}\text { Twenty-six } \\
\text { weeks }\end{array}$ & $\begin{array}{c}0.196 \pm \\
0.08\end{array}$ & $\begin{array}{c}0.265 \pm \\
0.06\end{array}$ & 0.252 & $\begin{array}{c}68 \pm \\
7\end{array}$ & $\begin{array}{c}55 \pm \\
8\end{array}$ & 0.0573 & $\begin{array}{c}2.1 \pm \\
0.3\end{array}$ & $\begin{array}{c}2.6 \pm \\
0.3\end{array}$ & 0.295 & $\begin{array}{c}0.202 \pm \\
0.06\end{array}$ & $\begin{array}{c}0.245 \pm \\
0.04\end{array}$ & 0.578 \\
\hline
\end{tabular}

Table 2. Shannon-Weaver diversity indices, abundance, species richness, and evenness, each \pm standard error of the mean, for treated and control plots after each survey shown with associated $t$ and $p$ values of two-tailed t-tests with 9 degrees of freedom. Bold values indicate statistical significance. 
Trends in treated plot recovery as represented by decreasing Euclidean distance

Before ivy removal, control and treated plots had an average Euclidean distance of 13.4. The greatest average Euclidean distance (44.2) was observed four weeks after ivy removal, and subsequent values decreased, first sharply (21.8 after 10 weeks), and then gradually (17.0 after 30 weeks; Figure 4).

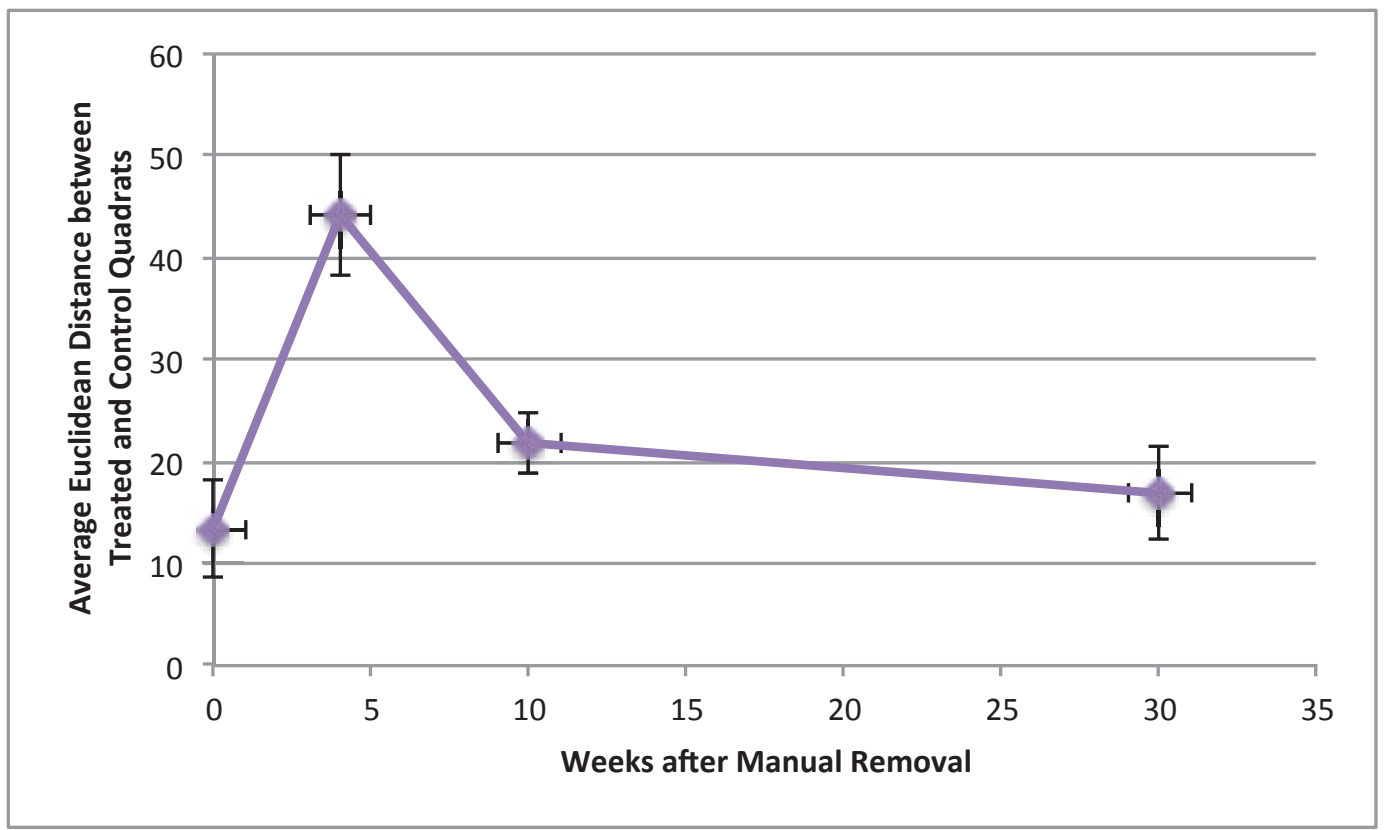

Figure 4. Euclidean distances between treated and control plots at each survey. The occurrence of a large initial dissimilarity followed by quick recovery is consistent with t-test data for plant diversity and abundance. Error bars show standard errors of the mean.

\section{DISCUSSION}

Four weeks after manual removal, treated plots were less diverse and hosted a lower abundance of native plants than control plots. After ten weeks, diversity indices of treated and control plots were no longer significantly different, and treated plots showed greater abundance of plant cover than controls. This trend persisted at twenty-six weeks after treatment. Treated and control plots were not significantly different in species richness or evenness (Table 2). These results suggest that the act of manual ivy removal temporarily disturbs plant life, but the negative effects are overcome as quickly as ten weeks after treatment, at which time a positive trend in native plant abundance may arise. Euclidean distance calculations confirmed the trend of an initial disturbance followed by quick recovery. Euclidean distance increased $230 \%$ four weeks after ivy removal, but decreased rapidly to approach within $30 \%$ of the initial distance after ten weeks (Figure 4). This suggests that the treatment initially increased dissimilarity between treated and control plots, but the effect decreased after ten and twenty-six weeks. Therefore, manual removal as a treatment method appears to be at least moderately long lasting and may allow further positive effects on native seedling recruitment.

It is also encouraging to note that, except for ivy, only native species emerged after ivy removal, though this may have been influenced by the location of the plots within established native communities and without close proximity to other exotic species. Furthermore, despite the dominance of ivy in the surrounding space, no ivy seedlings were observed within treated plots throughout the duration of the study. Thus, it appears ivy has either not established a dominant presence in the 
seed bank or that its seeds are not able to sprout sooner than native seeds. Even so, ivy was observed in treated plots after removal in the form of pioneering shoots, achieving an average of 12 percent cover by twenty-six weeks after removal. From the lack of ivy seedlings and the fact that ivy can establish subterranean roots from its shoots, ${ }^{24}$ vegetative reproduction appears to be the most significant contributing factor to the dominance of ivy in this region.

While the results of this experiment indicate that manual ivy removal has positive effects on native plant abundance after a period of at least ten weeks, it is not realistic to assume this is representative of the long-term effects of manual ivy removal. Ten weeks after treatment, many plants had not yet had the chance to sprout, nor had an entire cycle of seed dispersal-and thus seed bank formation - and germination of forest plants had been allowed to occur. Later in the season, after twenty-six weeks, the spring growth died off and the soil was dry and unfavorable for new plant growth. Accordingly, little plant life was observed other than ivy during the third survey (average of 68 abundance in test plots, in comparison to second survey average abundance of 137). An entire cycle of seeding, germination, and emergence was not reflected in this study, and thus diversity indices did not portray the total diversity of plant life in plots throughout the season, especially through the fall and winter months. It is postulated that more positive results, such as greater native plant diversity and abundance in cleared plots, would be likely to develop after a year or more of community recovery if ivy did not reclaim the cleared areas. Though prior studies have indicated that ivy does not inhibit seed bank formation, ${ }^{20}$ natural remediation time after treatment may be necessary to overcome the disruptive effects of pulling ivy to the soil and surrounding plant life.

Another limitation of this current data set is that many seedlings emerging during the surveys were only observed as a pair of cotyledons and were not identifiable. This led to a large collection of similar individuals being lumped into one or more "unknown" categories, which might have included more than one species. Indeed, some individuals placed in this category during the first survey showed signs of being Hydrophyllum tenuipes, but were not recorded as such due to the uncertainty of the determination. Fortunately, both of these issues affected control and treated plots equally, so they did not likely compromise the validity of the conclusions.

Despite these limitations, the results of this study support two conclusions. First, manual ivy removal is disruptive to the plant community, having immediate adverse effects on diversity and abundance of native species. Considering how deeply embedded the ivy lattices were within the soil in some treated plots, this result could be expected, for detritus, plant matter, and soil were greatly disturbed in the attempt to remove all parts of the ivy (Figure 2). However, the longevity of the negative consequences appears short-lived and may be overcome by the positive effects ivy eradication, which leads to the second important implication: while the native plant community may suffer initially, recovery of diversity and abundance is rather rapid. This is consistent with the hypothesis that native species are more successful in the absence of non-native species, especially those as invasive as ivy. The greater abundance of native plants in treated versus control plots after twenty-six weeks further supports the hypothesis that native plants benefit from ivy removal. Possible explanations for this trend include increased light, nutrient, and space availability for native plants.

Two additional observations from this study remain to be mentioned, the first of which being variance in moss growth patterns. Although the data indicate a similar percent cover by mosses in treated and control plots, mosses tended to form much fuller mats in control plots than in treated plots. Mosses growing in treated plots were characterized by numerous small, filamentous individuals. Full recovery of moss mats in treated plots was not observed during the study period, which presents qualitative evidence of the disruptive effects of manual ivy removal.

Secondly, deer tracks and droppings indicated that defoliation observed throughout the site, which encumbered plot pair establishment, was likely caused by deer. This implies that deer in this area of Forest Park have been using ivy as a winter food source, which in turn suggests that local deer are accustomed to hederin, a secondary metabolite in ivy that normally suppresses herbivore appetite ${ }^{18}$ It is possible that this browsing damages ivy individuals in such a way that their growth 
may be hindered, or that defoliation followed by vegetative growth of surviving ivy may be contributing to the mesh-like network of ivy growth throughout the understory if new shoots grow over the older, defoliated woody stems. In either case, further investigation into the relationship of ivy to native herbivores is warranted.

Other future avenues of research include studying the effect of manual ivy removal on seedling recruitment in a different location in Forest Park. Likely because of the moist environment, the current site was characterized by an abundance of Hydrophyllum tenuipes, which itself may rapidly overshadow any slower-growing species. Setting up plots in a different location, perhaps nearer to established populations of local invasive species such as Geranium robertianum (herb Robert) or Rubus bifrons (Himalayan blackberry), would also be useful to determine whether successive invasion by nonnative species presents an obstacle for recovery after ivy removal. Moreover, the principal cause of ivy dominance in the PNW has yet to be determined and is instead often speculatively inferred. Like other invasive species, there are many possible mechanisms by which ivy may be achieving dominance in PNW forests, such as light competition, nutrient competition, allelopathy, or alteration of soil microbial composition. ${ }^{26}$ Understanding the underlying cause of ivy invasion may advance the development of an effective solution.

\section{CONCLUSION}

Given the archetypical pattern of ivy invasion in Forest Park relative to much of the $\mathrm{PNW},{ }^{25}$ this study has important implications for ivy control throughout the region. The results support the use of manual ivy removal to promote native plant success, though care should be taken to minimize initial habitat disturbance, although prevention may remain the ideal solution to the problem of ivy in the PNW.

\section{ACKNOWLEDGMENTS}

I thank Portland Parks and Recreation, especially natural resources ecologist Kendra PetersenMorgen, for permitting research at this site. Thanks also go to Dr. Christine Weilhoefer for methodological expertise and Blair Pearson for assistance in conducting field work.

\section{REFERENCES}

[1] Jones, C. and Reichard, S. (2009) Current and potential distributions of three non-native invasive plants in the contiguous USA, Nat Area J, 29(4), 332-343.

[2] USDA, NRCS (2013) The PLANTS Database, National Plant Data Team, http://plants.usda.gov/ core/profile?symbol=HEHE (accessed Nov 2013).

[3] Metcalfe, D. (2005) Hedera helix L., J Ecol, 93, 632-648.

[4] Yaman, B. (2009) Comparative wood anatomy of ivy-hosting and non-hosting oriental plane (Platanus orientalis L.), Plant Biosyst, 143(2), 252-257.

[5] Soll, J. (2005) Controlling English ivy (Hedera helix) in the Pacific Northwest, Global Invasive Species Team, The Nature Conservancy, http://www.invasive.org/gist/moredocs/hedhel02.pdf (accessed Feb 2015).

[6] Van Cowenberghe, R., Collet, C., Lacombe, E., and Gegout, J. (2011) Abundance response of western European forest species along canopy openness and soil pH gradients, Forest Ecol Manag, 262, 1483-1490.

[7] Dlugosch, K. (2005) Understory community changes associated with English ivy invasions in Seattle's urban parks, Northwest Sci, 79(1), 53-60.

[8] Thomas, L. K. (1980) Impact of three exotic plant species on a Potomac Island, Clemson University Libraries, [Online], 58-65 (accessed May 2014). 
[9] Shoup, S. and Whitcomb, C. E. (1981) Interactions between trees and ground covers, J Arboric, 7(7), 186-187.

[10] Reichard, S. (2000) Hedera helix, in Invasive Plants of California's Wildlands, (C. C. Bossard, J. M. Randall, and M. C. Hoshovsky, Eds.) pp. 212-215, University of California Press, Berkeley, CA.

[11] Okerman, A. (2000) Combating the "ivy desert": the invasion of Hedera helix (English ivy) in the Pacific Northwest United States, Restoration and Reclamation Review - Student Online Journal, 6(4), http://conservancy.umn.edu/bitstream/handle/11299/59738/6.4. Okerman.pdf?sequence=1 (accessed Feb 2015).

[12] Jones, C. C., Acker, S. A., and Halpern, C. B. (2010) Combining local- and large-scale models to predict the distributions of invasive plant species, Ecol Appl, 20(2), 311-326.

[13] Vidra, R., Shear, T., and Wentworth, T. (2006) Testing the paradigms of exotic species invasion in urban riparian forests, Nat Area J, 26(4), 339-350.

[14] Chapin, S., Walker, B., Hobbs, R., Hooper, D., Lawton, J., Sala, O., and Tilman, D. (1997) Biotic control over the functioning of ecosystems, Science, 277, 500-504.

[15] Derr, J. F. (1993) English ivy (Hedera helix) response to postemergence herbicides, J Environ Hortic, 11(2), 45-48.

[16] Yang, Q., Wehtje, G., Gilliam, C., McElroy, J., and Sibley, J. (2013) English ivy (Hedera helix) control with postemergence-applied herbicides, IPSM, 6(3), 411-415.

[17] Swearingen, J. and Diedrich, S. (2006) English Ivy (Hedera helix L.) Plant Conservation Alliance's Alien Plant Working Group, http://www.nps.gov/plants/alien/fact/hehe1.htm (accessed Feb 2015).

[18] Ingham, C. and Borman, M. (2010) English ivy (Hedera spp., Araliaceae) response to goat browsing, IPSM, 3(2), 178-181.

[19] Young, S., Simmons, R., and Hamblin-Katnik, C. (2012) Instructions for removing English ivy and discussion of safety, City of Alexandria Dept. Recreation, Parks, and Cultural Activities, Alexandria, Virginia, http://alexandriava.gov/48838 (accessed Nov 2014).

[20] Biggerstaff, M. S. and Beck, C. W. (2007) Effects of English ivy (Hedera helix) on seed bank formation and germination, Am Midl Nat, 157, 250-257.

[21] Bauerle, T. and Chalker-Scott, L. (2001) Relative effectiveness of control mechanisms for juvenile English ivy (Hedera helix) as measured by leaf respiration and root-crown starch content, Hortscience, 36(3), 431

[22] Pojar, J. (2004) Plants of the Pacific Northwest Coast, revised ed. Lone Pine Publishing, Auburn, WA.

[23] Hitchcock, C. L. (1973) Flora of the Pacific Northwest: An Illustrated Manual. University of Washington Press, Seattle, WA.

[24] Melzer, B., Seidel, R., Steinbrecher, T., and Speck, T. (2011) Structure, attachment properties, and ecological importance of the attachment system of English ivy (Hedera helix), J Exp Bot, [Online], err260v1-err260.

[25] City of Portland, Oregon. (2014) The Ivy Files, Parks and Recreation, https://www.portlandoregon.gov/parks/47820 (accessed May 2014).

[26] Bennett, A., Thomsen, M., and Strauss, S. (2011) Multiple mechanisms enable invasive species to suppress native species, Am J Bot, 98(7), 1086-1094. 


\section{ABOUT THE STUDENT AUTHOR}

Katelin D. Stanley is a recent biology graduate from the University of Portland in Portland, Oregon and is currently a Ph.D. student at the Florida State University. Having had the opportunity to participate in several research projects during her undergraduate years, Katelin is eager to pursue a future in ecological and biodiversity research. Her scientific interests include ecology and plant systematics, with special emphasis on the use of biological databases such as herbaria.

\section{PRESS SUMMARY}

The two exotic vine species English and Irish ivy (Hedera helix and H. hibernica, respectively) have invaded natural areas in the Pacific Northwest, demonstrating rampant growth and rapid climbing ability. The most common strategy for ivy control is currently removal with clippers and by hand, though the potential consequences of this method have not been well studied. The purpose of this study was to evaluate the effectiveness of this method by investigating its effects on native plant life. Results indicate that manual removal is at first disruptive to native plants, but the negative effects decrease after ten weeks and are replaced by greater native plant abundance. This supports the use of manual ivy removal to control ivy invasions.

\section{$\mathrm{A} J \mathrm{R}$ Volume 12 | Issue 4 | November 2015}

